\title{
Barriers to Implementation of Case Management for Patients With Dementia: A Systematic Mixed Studies Review
}

\author{
Vladimir Khanassov, MD \\ Isabelle Vedel, $M D, P b D$ \\ Pierre Pluye, MD, PbD \\ Department of Family Medicine, McGill \\ University, Montreal, Canada
}

Conflicts of interest: authors report none.

\section{CORRESPONDING AUTHOR}

Isabelle Vedel, MD, PhD

Department of Family Medicine

McGill University

5858 Côte-des-Neiges, 3rd Floor, Suite 300

Montreal, Quebec, H3S 1Z1

isabelle.vedel@mcgill.ca

\begin{abstract}
PURPOSE Results of case management designed for patients with dementia and their caregivers in community-based primary health care (CBPHC) were inconsistent. Our objective was to identify the relationships between key outcomes of case management and barriers to implementation.
\end{abstract}

METHODS We conducted a systematic mixed studies review (including quantitative and qualitative studies). Literature search was performed in MEDLINE, PsycINFO, Embase, and Cochrane Library (1995 up to August 2012). Case management intervention studies were used to assess clinical outcomes for patients, service use, caregiver outcomes, satisfaction, and cost-effectiveness. Qualitative studies were used to examine barriers to case management implementation. Patterns in the relationships between barriers to implementation and outcomes were identified using the configurational comparative method. The quality of studies was assessed using the Mixed Methods Appraisal Tool.

RESULTS Forty-three studies were selected (31 quantitative and 12 qualitative). Case management had a limited positive effect on behavioral symptoms of dementia and length of hospital stay for patients and on burden and depression for informal caregivers. Interventions that addressed a greater number of barriers to implementation resulted in increased number of positive outcomes. Results suggested that highintensity case management was necessary and sufficient to produce positive clinical outcomes for patients and to optimize service use. Effective communication within the CBPHC team was necessary and sufficient for positive outcomes for caregivers.

CONCLUSIONS Clinicians and managers who implement case management in CBPHC should take into account high-intensity case management (small caseload, regular proactive patient follow-up, regular contact between case managers and family physicians) and effective communication between case managers and other CBPHC professionals and services.

Ann Fam Med 2014;12:456-465. doi: 10.1370/afm.1677.

\section{INTRODUCTION}

$\mathrm{D}$ ementia represents a global health priority. The number of people affected has risen exponentially, and its impact on patients, families, and society has been heavy. ${ }^{1,2} \mathrm{~A}$ recent systematic review reported that 35.6 million people lived with dementia worldwide in 2010, a number that will double every 20 years. ${ }^{3}$

The family physician is most often the first physician (72\%) consulted for dementia-related problems. ${ }^{4,5}$ The Canadian community-based primary health care (CBPHC) is not yet prepared to deal with the growing prevalence of this disease. ${ }^{6-9}$ Most patients do not receive a diagnosis and appropriate service in CBPHC. ${ }^{5}$ When patients were screened for cognitive impairment, only $25 \%$ with moderate or severe impairment had this condition recorded in their medical charts by family physicians..$^{10}$ Inadequate needs assessment and poor coordination of primary care services are additional factors that contribute to this problem. ${ }^{11}$ 
One approach taken to improve the care provided to this population is case management, which is aimed at transforming the health care system from service-based care to demand-directed care. ${ }^{12,13}$ Case management is "a collaborative process of assessment, planning, facilitation, care coordination and advocacy for options and services to meet an individual's and family's comprehensive health needs through communication and available resources to promote quality cost-effective outcomes." ${ }^{\prime 14}$

Case management as a multicomponent intervention varies across different countries and can include education and counseling, as well as close follow-up by a team of health care professionals or individual case managers. ${ }^{12,13,15-23}$ During the past decades, several case management projects have been implemented in $\mathrm{CBPHC}$ to improve clinical outcomes for patients with dementia and to optimize resource utilization. ${ }^{12,13,15-23}$ Despite best intentions, however, case management efficacy varies across the studies. Several systematic reviews have drawn mixed and controversial conclusions concerning the overall impact of case management interventions and were unable to explain the heterogeneity of outcomes. ${ }^{8,24-27}$ For example, Pimouguet et al reported no evidence for reduction in hospitalization resources and health care expenditures. ${ }^{24} \mathrm{On}$ the contrary, Tam-Tham et al found a short-term positive effect on the risk to institutionalization. ${ }^{27}$ Another review showed improvement in satisfaction of patients and adherence to dementia guidelines. ${ }^{8}$

It has been shown that one factor hindering the efficacy of case management is barriers to implementation (eg, high turnover of staff), ${ }_{1}^{22,28,29}$ which can lead to the interventions having little or no effect. Although recent study results emphasize the importance of accounting for such barriers to implementation, ${ }^{30-32}$ they have been understudied in case management. ${ }^{33}$

Thus, the research question of our systematic review was as follows: for CBPHC patients with dementia, what are the relationships between the key outcomes of case management and barriers to implementation?

\section{METHODS}

This systematic mixed studies review includes studies with diverse designs (quantitative and qualitative) to evaluate complex interventions. ${ }^{34}$

\section{Eligibility Criteria}

The population of these studies encompassed people of any age and sex with any type of dementia (diagnosis code) and/or primary causes of cognitive impairment (symptom code indicating memory loss) residing in the community and receiving care from health care professionals involved in case management in a range of community settings (eg, patients' homes, physicians' offices). ${ }^{35}$

Types of interventions included case management comprising assessment, care planning, implementation, management, and regular follow-up. ${ }^{14,36}$

Intervention studies (quantitative) included assessing outcomes of case management for patients and caregivers (eg, randomized controlled trials) intervention and nonintervention studies included evaluating barriers to case management implementation (eg, qualitative and mixed methods).

Types of outcome measures included clinical outcomes (behavioral symptoms, cognition, depression, functional status, health, quality of life, mortality), service use (nursing home, hospital and emergency department admission, length of hospital stay), caregiver outcomes (depression, burden, strain, quality of life, health), satisfaction (patient-caregiver dyad, health care professionals), and cost-effectiveness.

\section{Search Strategy, Study Selection, and Data Extraction}

In accordance with PRISMA statement standards, ${ }^{37} \mathrm{a}$ specialized librarian conducted a literature search for publications in English or French listed in MEDLINE, PsycINFO, Embase, and the Cochrane Library that were published between 1995 (official publication of the case management standards of practice) $)^{14}$ and August 31, 2012. The first search was expanded using snowballing techniques looking at the references in the selected studies and systematic reviews. Moreover, all companion articles of the main studies were searched (including articles on the intervention's implementation). To assure the exhaustiveness of our search, we additionally looked for the citations in the Scopus database. The main key terms used to identify relevant studies were case management or care management or case coordination. An example of our search in PsycINFO is presented in Supplemental Appendix 1.

Based on the eligibility criteria, titles and abstracts were retrieved with examination of the relevant fulltext copies independently by 2 reviewers (V.K., I.V.). Differences in the coding were resolved by consensus or referred to a third reviewer (P.P.). Kappa scores were calculated to estimate interreviewer reliability. ${ }^{38}$

Two researchers (V.K., I.V.) independently extracted the following information from each study: characteristics of the study participants (eg, sample size, diagnosis), type of intervention (components), characteristics of the study (eg, design), and outcomes Estimated outcomes in the included studies were categorized and coded as positive (effect was significant) or no effect (no effect or nonsignificant). 


\section{Quality Assessment}

Two reviewers (V.K., P.P.) assessed the quality of the studies independently by using the Mixed Methods Appraisal Tool (MMAT), which has been validated for the critical appraisal of studies with diverse designs. ${ }^{39,40}$ The quality of each included study was assessed against the MMAT criteria. Interrater reliability was calculated based on a weighted $\kappa$ statistic. ${ }^{41}$ Studies of poorer quality were not excluded, but a sensitivity analysis was performed to assess the impact of lower quality studies (with a score of 0 and 1 ) on the results.

\section{Synthesis}

We used a sequential explanatory synthesis design developed by Thomas et $\mathrm{a}^{42}$ to integrate qualitative evidence with quantitative findings.

\section{Quantitative Synthesis}

We identified the key outcomes of the studies. A metaanalysis was not possible because of the heterogeneity of the interventions (eg, different health care professionals involved in the patient-caregiver dyad's care team vs individual case management).

To evaluate the magnitude of the positive outcomes, however, we calculated the effect size (the Cohen method) ${ }^{41}$ Furthermore, we developed 3 main groups of composite outcomes (clinical outcomes, service use, and outcomes for caregivers). They were dichotomized as either no effect (score $=0$, no positive outcomes in the group) or positive (score $=1$, at least 1 positive outcome in the group). According to the Cochrane recommendations, the results of randomized controlled trials and nonrandomized studies were analyzed and presented separately. ${ }^{43,44}$

\section{Qualitative Synthesis}

Grol et $a l^{30}$ underscored the potential role played by barriers to implementation in influencing outcomes. We identified these barriers based on the classification of Chaudoir et $\mathrm{al}^{45}$ : barriers at the level of the organization (aspects of the organization in which the innovation is implemented, eg, organizations that misunderstand the case manager role); barriers at the level of the physician (characteristics of the individual physician implementing the innovation, eg, lack of training); and barriers at the level of the innovation (aspects of the innovation, eg, a short engagement period). As one of the main characteristics of case management, we evaluated case management intensity using the method developed by Pacala et al. ${ }^{46}$ More details are available in Supplemental Appendix 2.

Integration of Quantitative and Qualitative Syntheses We identified whether the quantitative studies had addressed barriers to implementation by matching the qualitative synthesis results with qualitative synthesis findings (cross-study synthesis). ${ }^{42}$ Two reviewers (V.K., I.V.) performed this analysis independently, with calculation of $\kappa$ scores to estimate interreviewer reliability. ${ }^{38}$

We applied the configurational comparative method $^{47}$ to build barrier-outcome configurations (Boolean algebra) (for randomized controlled trials only). According to this method, it is necessary for a certain condition or combination of conditions to be present for an outcome to occur. ${ }^{47}$ We identified patterns in the relationships between conditions (addressed and nonaddressed barriers to case management implementation, eg, case management intensity) and outcomes (eg, fewer hospitalizations). To build configurations, we grouped studies that shared a given outcome (no effect or positive effect), and we searched for their shared conditions (barriers addressed or not addressed).

\section{RESULTS}

\section{Search Results}

Of 12,746 references, 43 studies were included in the review (56 publications) (Figure 1).

Of the included studies, 31 were quantitative (21 randomized controlled trials, 6 nonrandomized studies, $^{68.73}$ and 4 descriptive studies ${ }^{9,74-77}$ ), and 12 were qualitative studies (11 qualitative descriptive studies, ${ }^{78-89}$ and 1 multiple case study ${ }^{90}$ ) (Table 1 , and Supplemental Tables 1 and 2). Patients' mean age was 78.5 years, and they had mild to moderately severe cognitive deficiencies.

\section{Description of the Case Management Interventions}

Apart from the main components of the case management intervention, ${ }^{14}$ some studies used specific therapy (reminiscence, cognitive stimulation), ${ }^{59,62}$ a focus on anticholinesterase inhibitors prescriptions, ${ }^{12}$ and a Web-based system communication (Supplemental Table 1). ${ }^{12,13}$ Moreover, the heterogeneity of the studies was due to the health care professionals involved in case management team ${ }^{\dagger} \mathrm{vs}$ individual case management $^{\ddagger}$ (Supplemental Tables 1 and 2).

In most of the studies communication between health care professionals occurred via referral made by case managers. In a few studies the communication was based on regular meeting and via the Web-based system. $12,13,67,73$

The quantitative descriptive studies did not provide new or contradictory information and are not presented. More details are available in Supplemental Appendix 3.

\footnotetext{
* References 12, 13, 15, 16, 18-20, 22, 23, 28, 29, 48-67.

† References 12, 13, 28, 29, 48, 53, 56-60, 63, 67-69, 73-75, 77

‡ References 17, 22, 23, 51, 52, 62, 66, 70-72, 91 .
} 


\section{Quantitative Synthesis: Key Outcomes}

Evidence From Randomized Controlled Trials

For clinical outcomes, 4 of 10 trials showed a decrease in the frequency of behavioral symptoms of dementia in the case management intervention group (mean effect size, 0.88$)^{12,23,48,59}$ (Table 2). Only 2 of 7 trials reported a decrease in the depression symptoms. ${ }^{21,58}$
One of 5 trials showed an improvement in the functional status, ${ }^{67} 1$ of 3 showed an increase in quality of life (effect size $=0.3){ }^{13}$ and 1 of 4 showed a decrease in mortality (effect size $=0.2) .{ }^{67}$ There was no effect on cognition and perceived health.

Regarding service use, no effect on institutionalization was observed in 8 of 11 trials that evaluated this outcome (Table 2). 12,17,22,51,53,56,57,91 In the studies that showed a decrease in institutionalization, ${ }^{48,64,67}$ the mean effect size was small $(0.21){ }^{48,67}$

In 2 of 5 studies, hospital

Potentially relevant studies on all types of inter ventions identified and screened for retrieval from electronic search engines, title and abstract $(n=11,973)$

773 Additional search of qualitative and mixed methods studies on case management

11,465 Excluded based on title or abstract

Nonempirical articles (eg, editorials)

Reviews, protocols without data, current practice

Nonrelevant cognitive impairment (eg, Down syndrome, brain tumor, schizophrenia)

No intervention

Pathogenesis of the disease

Epidemiology of the disease

Experimental studies on animals

Studies in a nursing home, a hospital without a link to primary care, an assisted living facility, palliative care and respite care, a day care center, a club

Validity of screening tests

No data on outcomes

1,281 Potentially relevant studies on all types of interventions identified and screened for retrieval from electronic search engines, full text

\begin{tabular}{|l|l|}
\hline \multicolumn{1}{|c|}{} & $\begin{array}{l}1,238 \text { Excluded based on full text } \\
\text { Nonempirical articles (eg, editorials) } \\
\text { Reviews, protocols without data, current practice } \\
\text { No intervention } \\
\text { Nonrelevant cognitive impairment (eg, Down } \\
\text { syndrome, brain tumor, schizophrenia) } \\
\text { Studies in a nursing home, a hospital without a } \\
\text { link to primary care, an assisted living facility, } \\
\text { palliative care and respite care, a day care } \\
\text { center, a club } \\
\text { Specific intervention (eg, music therapy) with- } \\
\text { out organizational modification } \\
\text { Interventions for health care professionals } \\
\text { Quality improvement initiatives } \\
\text { Screening programs }\end{array}$ \\
\hline 43 Included in the final systematic review \\
\hline Refers to overall interreviewer reliability $\kappa . \quad$
\end{tabular}

admission decreased (mean effect gency department admission was shown in 1 of 3 studies (effect size $=0.17),{ }_{1}^{21}$ and a decrease in length of hospital stay was shown in both of the studies that evaluated this outcome (mean effect size $=1.06) \cdot{ }^{23,48}$

Concerning outcomes for caregivers, 5 of 10 studies showed a decrease in depression (mean effect size $=0.68),{ }^{15,21,29,59,65}$ and 4 of 11 showed a decrease in burden (mean effect size $=0.5)\left(\right.$ Table 2). ${ }^{15,23,48}$ Impacts on quality of life (mean effect size $=0.63){ }_{1}^{23,48}$ health (mean effect size $=0.32)_{1}^{12,28}$ and strain (effect size $=0.18)^{21}$ were less clear because of sparse evidence.

Only 1 of 4 studies assessing the satisfaction of caregivers reported an increase (Table 2). ${ }^{22}$ Evidence on health care professionals' satisfaction was sparse. ${ }^{63}$

All 5 trials found no evidence of cost savings (Table 2). ${ }^{15,55,57,58,63}$

\section{Evidence From Nonrandomized Studies}

The results from nonrandomized studies showed findings similar to those of randomized controlled trials except for 2 outcomes: 2 studies showed cost-effectiveness of case management, ${ }^{69,71}$ and 1 study achieved improvement in cognition. ${ }^{68}$

\section{Qualitative Synthesis: Barriers to Implementation}

The results of the barriers to implementation are displayed in Supplemental Table $3 .{ }^{45}$ The most fresize $=0.66) .{ }^{21,23} \mathrm{~A}$ decrease in emer- 
Table 1. Characteristics of Included Qualitative Case Management Implementation Studies

\begin{tabular}{|c|c|c|c|}
\hline $\begin{array}{l}\text { Author, Year } \\
\text { Country }\end{array}$ & Study Design & Sample & Characteristics of the Intervention \\
\hline $\begin{array}{l}\text { Adams, } 1996^{78} \\
\text { United Kingdom }\end{array}$ & $\begin{array}{l}\text { Qualitative descriptive } \\
\text { Thematic analysis }\end{array}$ & 14 Case managers & $\begin{array}{l}\text { Case management focusing on dementia } \\
\text { patients and their caregivers }\end{array}$ \\
\hline $\begin{array}{l}\text { Black, } 2007,79 \\
2008^{80} \\
\text { United States }\end{array}$ & $\begin{array}{l}\text { Qualitative descriptive } \\
\text { Thematic analysis }\end{array}$ & 27 Community-based case managers & $\begin{array}{l}\text { Case management focused on the diseases of } \\
\text { older persons, including dementia } \\
\text { Focus on advance care planning skills of case } \\
\text { mangers as a part of their functions }\end{array}$ \\
\hline $\begin{array}{l}\text { Bogardus, } 1998^{81} \\
\text { United States }\end{array}$ & $\begin{array}{l}\text { Qualitative descriptive } \\
\text { Constant comparative } \\
\text { method }\end{array}$ & $\begin{array}{l}10 \text { Sets of participants (one set: patient, } \\
\text { caregiver, case manager, clinician) }\end{array}$ & $\begin{array}{l}\text { Case management focused on dementia } \\
\text { patients and their caregivers }\end{array}$ \\
\hline $\begin{array}{l}\text { Gibson, } 2007^{82} \\
\text { United Kingdom }\end{array}$ & $\begin{array}{l}\text { Qualitative descriptive } \\
\text { Thematic analysis }\end{array}$ & $\begin{array}{l}10 \text { Dyads (patient with mild to moderate } \\
\text { dementia and caregiver) receiving service } \\
\text { either via a hospital-based memory clinic } \\
\text { or a community-based nursing service }\end{array}$ & $\begin{array}{l}\text { Comparison of a community-based and clinic- } \\
\text { based memory service }\end{array}$ \\
\hline $\begin{array}{l}\text { Liebel, } 2012^{84} \\
\text { United States }\end{array}$ & $\begin{array}{l}\text { Qualitative descriptive } \\
\text { Thematic analysis }\end{array}$ & 19 Patients & $\begin{array}{l}\text { Secondary analysis of Medicare primary and } \\
\text { consumer-directed care. Demonstration } \\
\text { designed for patients with disabilities, includ- } \\
\text { ing cognitive impairment }(68 \%)\end{array}$ \\
\hline $\begin{array}{l}\text { McCrae, } 2011^{85} \\
\text { United Kingdom }\end{array}$ & $\begin{array}{l}\text { Convergent design } \\
\text { Thematic analysis }\end{array}$ & $\begin{array}{l}33 \text { Health care professionals (nurses, occu- } \\
\text { pational therapist, psychiatrists, psychol- } \\
\text { ogist, support workers, team leaders) at } \\
6 \text { months, and } 27 \text { at } 24 \text { months }\end{array}$ & $\begin{array}{l}\text { Evaluation of "Improving the Quality of Care } \\
\text { for Older People in Lambeth" impact from } \\
\text { staff perspectives: did it help or hinder in } \\
\text { performing their roles }\end{array}$ \\
\hline $\begin{array}{l}\text { Netting, } 1999^{86} \\
\text { United States }\end{array}$ & $\begin{array}{l}\text { Qualitative descriptive } \\
\text { Thematic analysis }\end{array}$ & $\begin{array}{l}36 \text { Different participants in case manage- } \\
\text { ment: physicians, case managers, case } \\
\text { assistants, practice managers, office staff }\end{array}$ & $\begin{array}{l}\text { Case management focused on the diseases of } \\
\text { older persons, including dementia }\end{array}$ \\
\hline $\begin{array}{l}\text { Seddon, } 2001^{87} \\
\quad \text { United Kingdom }\end{array}$ & $\begin{array}{l}\text { Qualitative descrip- } \\
\text { tive/Latent content } \\
\text { analysis }\end{array}$ & 8 Care managers and 64 caregivers & $\begin{array}{l}\text { Case management focused on caregiver's assess- } \\
\text { ment (ability to care and continue care, coping } \\
\text { ability, relationship with a care recipient) }\end{array}$ \\
\hline $\begin{array}{l}\text { Waugh, } 2009^{89} \\
\text { Australia }\end{array}$ & $\begin{array}{l}\text { Qualitative descriptive } \\
\text { Thematic analysis }\end{array}$ & $\begin{array}{l}5 \text { Staff workers of the Mercy Community } \\
\text { Care agency: } 2 \text { managers, } 2 \text { case man- } \\
\text { agers, one outreach worker }\end{array}$ & $\begin{array}{l}\text { Case management for dementia patients who } \\
\text { live alone }\end{array}$ \\
\hline $\begin{array}{l}\text { Minkman, } 2009^{90} \\
\text { The Netherlands }\end{array}$ & $\begin{array}{l}\text { Multiple case study } \\
\text { Thematic analysis }\end{array}$ & 9 Case managers & $\begin{array}{l}\text { Case management focused on dementia } \\
\text { patients and their caregivers }\end{array}$ \\
\hline
\end{tabular}

quently reported barriers were at the organization and physician levels.

There was confusion about who was responsible for the delivery of services for elderly persons because health care professionals misunderstood the case manager role..$^{9,60,78-80,83-88,90}$ Insufficient communication among health care professionals resulted in long-term objectives not being achieved in a timely manner, ${ }^{9,29,78-90}$ and training in geriatrics was lacking. ${ }^{9,28,79,80,82,83,86-90}$ Case management lacked an impact on the desired outcomes because it was not integrated into the current health care system, ${ }^{9,88,90}$ and family physicians and case managers were in different locations. ${ }^{82,84,86}$

The case management approach changed from proactive to more reactive (focus on dealing with crises) because of large caseloads..$^{79,80,90}$ Time constraints resulted in noncomprehensive and fragmented care provided to the patient-caregiver dyad. ${ }^{79,80,83,87,88}$
Turnover of case managers caused unstable relationships between the patient-caregiver dyad and the case manager, which resulted in less-effective care. ${ }^{9,22,86}$ Timely recognition of dementia and support during early stages of the disease were absent because family physicians were reluctant to be involved in dementia care. ${ }^{13,85,86}$

\section{Integration of Findings from Quantitative and Qualitative Studies}

\section{Barrier-Outcome Matching}

Based on the cross-study synthesis, the most addressed barriers in the intervention studies were the lack of a long intervention duration, $\$$ the need for high-intensity case management, ${ }^{\mathbb{f}}$ insufficient communication," case manager and family physicians being in

§ References $12,13,15,21,23,29,48,51,56,57,63-69,71,91$. I References 12, 13, 21, 23, 48, 49, 56, 57, 59, 60, 62, 67, 68, 70, 73. || References 12, 13, 21, 23, 28, 29, 48, 49, 53, 56-59, 68, 70, 73. 
different locations, ${ }^{* *}$ and a lack of health care professionals with geriatrics training. ${ }^{\dagger \dagger}$

When matching the studies on barriers to intervention studies, findings suggest that addressing these barriers is associated with better outcomes: the studies with more barriers addressed resulted in more positive outcomes (agreement $\kappa=0.94$; CI, 0.82-1.1). ${ }^{\ddagger \neq}$ More details are at Supplemental Appendix 4.

\section{Barrier-Outcome Configurations} Using the configurational comparative method, we identified the conditions with the most important influence on outcomes (Supplemental Table 4). The configurations suggest that high-intensity case management is necessary and sufficient both to produce positive clinical outcomes and to optimize service use, and that effective communication is necessary and sufficient to achieve positive outcomes for caregivers.

Other factors may play a positive role, but the evidence is sparse. The combination of effective communication among health care professionals and training case managers in geriatrics may produce positive clinical outcomes (1 study). The combination of a long intervention (at least 12 months) and locating the case manager in a CBPHC setting may lead to appropriate service use outcomes (1 study). A long duration of case management may produce positive outcomes for caregivers ( 2 studies). A small number of studies ${ }^{12,13,56,57,60}$ (called outliers), however, did not follow the same pattern of configurations that can be explained by other factors (Supplemental Table 4).

\section{Quality of Evidence}

Overall, the quantitative and qualitative studies proved to be of high

\footnotetext{
** References 12, 13, 23, 28, 48, 53, 59, 63-69, 73. t† References 12, 13, 28, 29, 56-59, 62, 70, 72, 73. 㧊 References 12，13，21，23，28，29，48，58，59，63，
} $65,67,68$.

Clinical outcomes

Depression

Cognition IADL)

Quality of life

Mortality

Service use visit

Burden

Depression

Strain

Quality of life

Satisfaction

Caregivers

Cost-effectiveness

Other outcomes guidelines textual information).
Table 2. Outcomes in the Randomized Controlled Trials

\begin{tabular}{|c|c|c|c|}
\hline & Randomizec & Controlled Trial & \\
\hline Outcome & $\begin{array}{l}\text { No. Measuring } \\
\text { the Outcome }\end{array}$ & $\begin{array}{l}\text { No. With a Positive } \\
\text { Outcome }\end{array}$ & $\begin{array}{l}\text { of Positive } \\
\text { Outcome }\end{array}$ \\
\hline
\end{tabular}

Behavioral/psychological

symptoms of dementia

10

$0.15^{48}$

$0.6^{12}$

$1.25^{23}$

$1.5^{59}$

7

21

8

$58^{\mathrm{b}}$

Functional status (ADL,

Perceived health

Hospitalization rate

Nursing home placement

11

2

Emergency department

Outcomes for caregivers

$0.03^{15}$

$0.29^{48}$

$1.17^{23}$

$58^{\mathrm{b}}$

10

5

$0.04^{15}$

$0.18^{21}$

$1.029,65$

$1.5^{59}$

1

Perceived health

6

$0.18^{21}$

$0.24^{28}$

$0.4^{12}$

6

$0.28^{48}$

$0.97^{23}$

Health care professionals

Medication management

Adherence to dementia

Dementia detection rate $22^{\mathrm{b}}$

NA

NA

$1.07^{12}$

$0.65^{13}$

$0.47^{53}$

$\mathrm{ADL}=$ activities of daily living; $\mathrm{IADL}=$ instrumental activities of daily living; $\mathrm{NA}=$ not applicable.

a Effect size: $<0.2$ = weak effect; $0.2-0.5=$ small effect; $0.5-0.8=$ intermediate effect; $>0.8=$ large effect. ${ }^{b}$ Insufficient data to calculate the effect size (eg, number of participants missing in comparison groups, only 


\section{DISCUSSION}

This systematic mixed studies review is the first to assess relationships between the key outcomes of case management and barriers to its implementation for patients with dementia in CBPHC. Previous systematic reviews highlighted the discrepancy of the outcomes across dementia case management interventions and questioned the efficacy of this intervention to produce desired clinical and service use outcomes. ${ }^{8,24,27}$

The main novelty and strength of our review are to integrate findings of studies with diverse designs so we can identify possible causes of this discrepancy and conditions that can help increase the overall efficacy of dementia case management.

According to Grol et al, ${ }^{30}$ implementation barriers affect outcomes, and they have been insufficiently studied..$^{33}$ Interpretations of outcomes depend on how well the intervention was designed and implemented in the care setting. ${ }^{31}$ A good implementation is associated with a better likelihood that programs will achieve more prominent results and superior benefits for participants. ${ }^{31}$ Thus, to explain the limited efficacy of case management, we identified barriers to its implementation at the level of the organization, the health care clinician, and the innovation. In addition, our configurations have shown that interventions that better address barriers produce more-positive outcomes. Finally, 2 key conditions with the most important influence on the case management outcomes were identified: high-intensity case management is associated with positive clinical outcomes and optimized service use, and effective communication is associated with positive outcomes for caregivers.

Our results suggest that intensity of case management is a key factor for effective patient and service use outcomes. The main characteristics of high-intensity case management are (1) a small caseload (50 patients per full-time case manager) ${ }_{1}^{46}(2)$ regular meetings with patients and their caregivers $(50 \%$ of which are devoted to in-person communication), (3) education on health conditions, (4) close contact with family physicians, ${ }^{93}$ and (5) proactive and timely follow-up. ${ }^{94}$ In addition, case managers can play an important role in transitional care by following up with patients during hospitalizations and short-term institutionalizations. ${ }^{95}$

Another key factor in obtaining positive outcomes is effective communication among health care professionals (transparent referral system, regular meetings, web-based tracking system). ${ }^{96,97}$ Effective case management requires individuals with communication and collaboration skills. ${ }^{98}$ Caregivers need help "navigating in the system," especially at the onset of the disease, ${ }^{99}$ and they expect appropriate communication among health care professionals. Caregivers also need to be closely involved in the decision-making process. ${ }^{100}$ Our results suggest effective communication is also essential to improve outcomes for caregivers who are at risk of adverse outcomes (depression and increased mortality). ${ }^{101}$ Because a person with dementia may move to a long-term care facility sooner than anticipated when a caregiver experiences an intolerable level of stress, providing support to caregivers has a major effect on patient outcomes and service use. ${ }^{102}$

\section{Limitations}

It is possible that a study was not identified as a result of the search terms we used. We did not conduct a meta-analysis, because case management interventions have a variety of main components and involved health care professionals. The intrinsic nature of the configurational comparative method to split the evidence into subsets of studies with common conditions is another limitation. Furthermore, information on monitoring implementation and the actual level it achieved can be sparse or omitted from the original reports. These limitations can affect the overall generalization of our findings but do not prevent us to provide a portrait of the researched phenomenon.

\section{Recommendations}

It is essential to evaluate case management implementation in health care facilities. This evaluation should precede the assessment of outcomes so that any corrective actions can be undertaken, ideally at least 6 months after implementation, during the engagement period. Two key conditions should be taken into account. First, there should be high-intensity case management (small caseload, regular proactive patientcaregiver follow-up, and regular contact between case managers and family physicians or specialists). Second, there must be effective communication among all health care professionals and services caring for patients with dementia and their caregivers, including community-based organizations (eg, Alzheimer Association). Effective communication relies on an efficient referral system (eg, a Web-based tracking system) and timely support of family physicians and case managers by specialists in complex cases. Locating a case manager in the primary care facility can facilitate interaction and support.

To read or post commentaries in response to this article, see it online at http://www.annfammed.org/content/12/5/456.

Key words: case management; dementia; community-based primary health care; systematic mixed studies review; configurational comparative method

Submitted October 29, 2013; submitted, revised, April 15, 2014; accepted May 2, 2014. 
Funding support: This research received financial support from the Canadian Institute of Health Research (CIHR- \#KRS 119799). V. Khanassov received a MSc bursary from the Fonds de Recherche du Québec - Santé (FRQS\# 27978).

Previous presentation: This study was presented as a poster at the North American Primary Care Research Group (NAPCRG), New Orleans, Louisiana, November 2012; and at the Alzheimer Association International Conference, Boston, Massachusetts, July 2013.

Acknowledgments: The authors would like to thank Nadia Sourial, MSc, biostatistician, SOLIDAGE, McGill University - Université de Montréal Research Group on Frailty and Aging, for her assistance with statistical analysis; and Muriel Gueriton, specialized librarian, SOLIDAGE, McGill University - Université de Montréal Research Group on Frailty and Aging, for her assistance with literature search.

Supplementary materials: Available at http://www.AnnFamMed. org/content/12/5/456/suppl/DC1/.

\section{References}

1. Le Couteur DG, Doust J, Creasey H, Brayne C. Political drive to screen for pre-dementia: not evidence based and ignores the harms of diagnosis. BMJ. 2013;347:f5125.

2. Lobo A, Launer LJ, Fratiglioni L, et al; Neurologic Diseases in the Elderly Research Group. Prevalence of dementia and major subtypes in Europe: A collaborative study of population-based cohorts. Neurology. 2000;54(11)(Suppl 5):S4-S9.

3. Prince $M$, Bryce $R$, Albanese $E$, Wimo A, Ribeiro W, Ferri CP. The global prevalence of dementia: a systematic review and metaanalysis. Alzheimers Dement. 2013;9(1):63-75 e2.

4. Relkin N. Screening and early diagnosis of dementia. Am J Manag Care. 2000;6(22)(suppl):S1111-S1118; discussion S1119-S1124.

5. Knopman D, Donohue JA, Gutterman EM. Patterns of care in the early stages of Alzheimer's disease: impediments to timely diagnosis. J Am Geriatr Soc. 2000;48(3):300-304.

6. Institute of Medicine. Living Well with Chronic Illness: A Call for Public Health Action. Washington, DC: The National Academies Press; 2012.

7. Wortmann M. Dementia: a global health priority - highlights from an ADI and World Health Organization report. Alzheimers Res Ther 2012;4(5):40.

8. Koch T, lliffe $\mathrm{S}$. Dementia diagnosis and management: a narrative review of changing practice. Br J Gen Pract. 2011;61(589):e513-e525.

9. Verkade PJ, van Meijel B, Brink C, van Os-Medendorp H, Koekkoek $B$, Francke AL. Delphi research exploring essential components and preconditions for case management in people with dementia. BMC Geriatr. 2010;10:54.

10. Callahan CM, Hendrie HC, Tierney WM. Documentation and evaluation of cognitive impairment in elderly primary care patients. Ann Intern Med. 1995;122(6):422-429.

11. Boeckxstaens P, De Graaf P. Primary care and care for older persons: position paper of the European Forum for Primary Care. Qual Prim Care. 2011;19(6):369-389.

12. Callahan CM, Boustani MA, Unverzagt FW, et al. Effectiveness of collaborative care for older adults with Alzheimer disease in primary care: a randomized controlled trial. JAMA. 2006;295(18):2148-2157.

13. Vickrey BG, Mittman BS, Connor KI, et al. The effect of a disease management intervention on quality and outcomes of dementia care: a randomized, controlled trial. Ann Intern Med. 2006;145(10): 713-726.

14. Case Management Society of America. http://www.cmsa.org. Accessed October 10, 2013.
15. Newcomer R, Miller R, Clay T, Fox P. Effects of the Medicare Alzheimer's disease demonstration on Medicare expenditures. Health Care Financ Rev. 1999;20(4):45-65.

16. Newcomer R, Spitalny M, Fox P, Yordi C. Effects of the Medicare Alzheimer's Disease Demonstration on the use of community-based services. Health Serv Res. 1999;34(3):645-667.

17. Miller R, Newcomer R, Fox P. Effects of the Medicare Alzheimer's Disease Demonstration on nursing home entry. Health Serv Res. 1999;34(3):691-714

18. Yordi C, DuNah R, Bostrom A, Fox P, Wilkinson A, Newcomer R. Caregiver supports: outcomes from the Medicare Alzheimer's disease demonstration. Health Care Financ Rev. 1997;19(2):97-117.

19. Shelton P, Schraeder C, Dworak D, Fraser C, Sager MA. Caregivers' utilization of health services: results from the Medicare Alzheimer's Disease Demonstration, Illinois site. J Am Geriatr Soc. 2001;49(12): 1600-1605.

20. Fox P, Newcomer R, Yordi C, Arnsberger P. Lessons learned from the Medicare Alzheimer Disease Demonstration. Alzheimer Dis Assoc Disord. 2000;14(2):87-93.

21. Bass DM, Clark PA, Looman WJ, McCarthy CA, Eckert S. The Cleveland Alzheimer's managed care demonstration: outcomes after 12 months of implementation. Gerontologist. 2003;43(1):73-85.

22. Fortinsky RH, Kulldorff M, Kleppinger A, Kenyon-Pesce L. Dementia care consultation for family caregivers: collaborative model linking an Alzheimer's association chapter with primary care physicians. Aging Ment Health. 2009;13(2):162-170.

23. Chien WT, Lee YM. A disease management program for families of persons in Hong Kong with dementia. Psychiatr Serv. 2008;59 (4):433-436.

24. Pimouguet C, Lavaud T, Dartigues JF, Helmer C. Dementia case management effectiveness on health care costs and resource utilization: a systematic review of randomized controlled trials. J Nutr Health Aging. 2010;14(8):669-676.

25. Koch T, lliffe S, Manthorpe J, et al; CARE-DEM. The potential of case management for people with dementia: a commentary. Int J Geriatr Psychiatry. 2012;27(12):1305-1314.

26. Somme D, Trouve H, Dramé M, Gagnon D, Couturier Y, Saint-Jean $O$. Analysis of case management programs for patients with dementia: a systematic review. Alzheimers Dement. 2012;8(5):426-436.

27. Tam-Tham H, Cepoiu-Martin M, Ronksley PE, Maxwell CJ, Hemmelgarn BR. Dementia case management and risk of long-term care placement: a systematic review and meta-analysis. Int J Geriatr Psychiatry. 2013;28(9):889-902.

28. Dias A, Dewey ME, D'Souza J, et al. The effectiveness of a home care program for supporting caregivers of persons with dementia in developing countries: a randomised controlled trial from Goa, India. PLoS One. 2008;3(6):e2333.

29. Schoenmakers B, Buntinx F, Delepeleire J. Supporting family carers of community-dwelling elder with cognitive decline: a randomized controlled trial. Int J Family Med. 2010;2010:184152.

30. Grol RP, Bosch MC, Hulscher ME, Eccles MP, Wensing M. Planning and studying improvement in patient care: the use of theoretical perspectives. Milbank Q. 2007;85(1):93-138.

31. Durlak JA, DuPre EP. Implementation matters: a review of research on the influence of implementation on program outcomes and the factors affecting implementation. Am J Community Psychol. 2008; 41(3-4):327-350.

32. Fixsen DLNS, Blase KA, Friedman RM, Wallace F. Implementation Research: A Synthesis of the Literature. Tampa, FL: The National Implementation Research Network at the Louis de la Parte Florida Mental Health Institute, University of South Florida; 2005.

33. Callahan CM, Boustani MA, Weiner M, et al. Implementing dementia care models in primary care settings: The aging brain care medical home. Aging Ment Health. 2011;15(1):5-12. 
34. Popay J. Moving Beyond Effectiveness in Evidence Synthesis: Methodological Issues in the Synthesis of Diverse Sources of Evidence. London, England: National Institute for Health and Clinical Excellence; 2006.

35. Community-based primary health care. Canadian Institutes of Health Research. http://www.cihr.ca/e/43626.html. Accessed February 3, 2014.

36. Weiss ME. Case management as a tool for clinical integration. Adv Pract Nurs Q. 1998;4(1):9-15.

37. Moher D, Liberati A, Tetzlaff J, Altman DG; PRISMA Group. Preferred reporting items for systematic reviews and meta-analyses: the PRISMA statement. BMJ. 2009;339:b2535.

38. Gwet KL. Computing inter-rater reliability and its variance in the presence of high agreement. Br J Math Stat Psychol. 2008;61(Pt 1): 29-48.

39. Pluye $P$, Gagnon MP, Griffiths $F$, Johnson-Lafleur J. A scoring system for appraising mixed methods research, and concomitantly appraising qualitative, quantitative and mixed methods primary studies in Mixed Studies Reviews. Int J Nurs Stud. 2009;46(4):529-546.

40. Pace $R$, Pluye $P$, Bartlett $G$, et al. Testing the reliability and efficiency of the pilot Mixed Methods Appraisal Tool (MMAT) for systematic mixed studies review. Int J Nurs Stud. 2012;49(1):47-53.

41. Cohen J. A power primer. Psychol Bull. 1992;112(1):155-159.

42. Thomas J, Harden A, Oakley A, et al. Integrating qualitative research with trials in systematic reviews. BMJ. 2004;328(7446):1010-1012.

43. Henry D, Moxey A, O'Connell D. Agreement between randomized and non-randomized studies - the effects of bias and confounding. In: Proceedings frpm the 9th Annual Cochrane Colloquium; October 9-13, 2001; Lyon, France.

44. Reeves BC, Higgins JPT, Ramsay C, Shea B, Tugwell P, Wells GA. An introduction to methodological issues when including nonrandomised studies in systematic reviews on the effects of interventions. Res Synth Methods. 2013;4(1):1-11.

45. Chaudoir SR, Dugan AG, Barr CH. Measuring factors affecting implementation of health innovations: a systematic review of structural, organizational, provider, patient, and innovation level measures. Implement Sci. 2013;8:22.

46. Pacala JT, Boult C, Hepburn KW, et al. Case management of older adults in health maintenance organizations. J Am Geriatr Soc. 1995; 43(5):538-542.

47. Rihoux B, Ragin C. Configurational Comparative Methods: Qualitative Comparative Analysis (QCA) and Related Techniques. Thousand Oaks, CA: Sage Publications; 2009.

48. Chien WT, Lee IY. Randomized controlled trial of a dementia care programme for families of home-resided older people with dementia. J Adv Nurs. 2011;67(4):774-787.

49. Chodosh J, Berry E, Lee M, et al. Effect of a dementia care management intervention on primary care provider knowledge, attitudes, and perceptions of quality of care. J Am Geriatr Soc. 2006 54(2):311-317.

50. Chodosh J, Pearson ML, Connor KI, et al. A dementia care management intervention: which components improve quality? Am J Manag Care. 2012;18(2):85-94.

51. Chu P, Edwards J, Levin R, Thomson J. The use of clinical case management for early stage Alzheimer' patients and their families. Am J Alzheimers Dis Other Demen. 2000;15(5):284-290.

52. Clark PA, Bass DM, Looman WJ, McCarthy CA, Eckert S. Outcomes for patients with dementia from the Cleveland Alzheimer's Managed Care Demonstration. Aging Ment Health. 2004;8(1):40-51.

53. Clarkson P, Venables D, Hughes J, Burns A, Challis D. Integrated specialist assessment of older people and predictors of care-home admission. Psychol Med. 2006;36(7):1011-1021.

54. Connor KI, McNeese-Smith DK, Vickrey BG, et al. Determining care management activities associated with mastery and relationship strain for dementia caregivers. J Am Geriatr Soc. 2008;56(5):891-897.
55. Duru OK, Ettner SL, Vassar SD, Chodosh J, Vickrey BG. Cost evaluation of a coordinated care management intervention for dementia. Am J Manag Care. 2009;15(8):521-528.

56. Eloniemi-Sulkava U, Notkola IL, Hentinen M, Kivelä SL, Sivenius J, Sulkava R. Effects of supporting community-living demented patients and their caregivers: a randomized trial. J Am Geriatr Soc. 2001;49(10):1282-1287.

57. Eloniemi-Sulkava U, Saarenheimo M, Laakkonen ML, et al. Family care as collaboration: effectiveness of a multicomponent support program for elderly couples with dementia. Randomized controlled intervention study. J Am Geriatr Soc. 2009;57(12):2200-2208.

58. Enguídanos SM, Jamison PM. Moving from tacit knowledge to evidence-based practice: the Kaiser Permanente community partners study. Home Health Care Serv Q. 2006;25(1-2):13-31.

59. Hinchliffe AC, Hyman IL, Blizard B, Livingston G. Behavioural complications of dementia-can they be treated? Int J Geriatr Psychiatry. 1995;10(10):839-847.

60. Jansen AP, van Hout HP, Nijpels G, et al. Effectiveness of case management among older adults with early symptoms of dementia and their primary informal caregivers: a randomized clinical trial. Int J Nurs Stud. 2011;48(8):933-943.

61. Jansen AP, van Hout HP, van Marwijk HW, et al. (Cost)-effectiveness of case-management by district nurses among primary informal caregivers of older adults with dementia symptoms and the older adults who receive informal care: design of a randomized controlled trial [ISCRTN83135728]. BMC Public Health. 2005;5:133.

62. Lam LC, Lee JS, Chung JC, Lau A, Woo J, Kwok TC. A randomized controlled trial to examine the effectiveness of case management model for community dwelling older persons with mild dementia in Hong Kong. Int J Geriatr Psychiatry. 2010;25(4):395-402.

63. Laurant MG, Hermens RP, Braspenning JC, Sibbald B, Grol RP. Impact of nurse practitioners on workload of general practitioners: randomised controlled trial. BMJ. 2004;328(7445):927.

64. Mittelman MS, Haley WE, Clay OJ, Roth DL. Improving caregiver well-being delays nursing home placement of patients with Alzheimer disease. Neurology. 2006;67(9):1592-1599.

65. Mittelman MS, Roth DL, Coon DW, Haley WE. Sustained benefit of supportive intervention for depressive symptoms in caregivers of patients with Alzheimer's disease. Am J Psychiatry. 2004;161(5): 850-856.

66. Mittelman MS, Roth DL, Haley WE, Zarit SH. Effects of a caregiver intervention on negative caregiver appraisals of behavior problems in patients with Alzheimer's disease: results of a randomized trial. J Gerontol B Psychol Sci Soc Sci. 2004;59(1):27-34.

67. Parsons M, Senior H, Kerse N, et al. Should care managers for older adults be located in primary care? A randomized controlled trial. J Am Geriatr Soc. 2012;60(1):86-92.

68. Aupperle PM, MacPhee ER, Coyne AC, Blume J, Sanchez B. Health service utilization by Alzheimer's disease patients: a 2-year follow-up of primary versus subspecialty care. J Geriatr Psychiatry Neurol. 2003;16(1):15-17.

69. Challis D, von Abendorff R, Brown P, Chesterman J, Hughes J. Care management, dementia care and specialist mental health services: an evaluation. Int J Geriatr Psychiatry. 2002;17(4):315-325.

70. Cherry DL, Vickrey BG, Schwankovsky L, Heck E, Plauchm M, Yep R. Interventions to improve quality of care: the Kaiser Permanentealzheimer's Association Dementia Care Project. Am J Manag Care. 2004;10(8):553-560.

71. Hammer BJ. Community-based case management for positive outcomes. Geriatr Nurs. 2001;22(5):271-275.

72. Specht J, Bossen A, Hall GR, Zimmerman B, Russell J. The effects of a dementia nurse care manager on improving caregiver outcomes. Am J Alzheimers Dis Other Demen. 2009;24(3):193-207.

73. Stevenson G, Ewing $H$, Herschell J, Keith D. An enhanced assessment and support team (EAST) for dementing elders - review of a Scottish regional initiative. J Ment Health. 2006;15(2):251-258. 
74. Ghatak R. Unique support model for dementia patients and their families in a tertiary hospital setting: description and preliminary data. Clin Gerontol. 2011;(34):160-172.

75. Jedenius E, Johnell K, Fastbom J, Strömqvist J, Winblad B, Andreasen N. Dementia management programme in a community setting and the use of psychotropic drugs in the elderly population. Scand J Prim Health Care. 2011;29(3):181-186.

76. Jedenius E, Wimo A, Strömqvist J, Andreasen N. A Swedish programme for dementia diagnostics in primary healthcare. Scand J Prim Health Care. 2008;26(4):235-240.

77. Judge KS, Bass DM, Snow AL, et al. Partners in dementia care: a care coordination intervention for individuals with dementia and their family caregivers. Gerontologist. 2011;51(2):261-272.

78. Adams T. A descriptive study of the work of community psychiatric nurses with elderly demented people. J Adv Nurs. 1996;23(6): 1177-1184

79. Black K, Fauske J. Exploring influences on community-based case managers' advance care planning practices: facilitators or barriers? Home Health Care Serv Q. 2007;26(2):41-58.

80. Black K, Fauske J. Measuring case managers' advance care planning practice: translating focus group findings to survey development. Care Manag J. 2008;9(4):166-176.

81. Bogardus ST Jr, Bradley EH, Tinetti ME. A taxonomy for goal setting in the care of persons with dementia. J Gen Intern Med. 1998; 13(10):675-680.

82. Gibson GTA, Timlin A, Curran S, Wattis J. The impact of location on satisfaction with dementia services amongst people with dementia and their informal carers: a comparative evaluation of a community-based and a clinic-based memory service. Int Psychogeriatr. 2007;19(2):267-277.

83. Gladman JR, Jones RG, Radford K, Walker E, Rothera I. Personcentred dementia services are feasible, but can they be sustained? Age Ageing. 2007;36(2):171-176.

84. Liebel DV, Powers BA, Friedman B, Watson NM. Barriers and facilitators to optimize function and prevent disability worsening: a content analysis of a nurse home visit intervention. J Adv Nurs. 2012;68(1):80-93.

85. McCrae N, Banerjee S. Modernizing mental health services for older people: a case study. Int Psychogeriatr. 2011;23(1):10-19.

86. Netting F, Williams F. Implementing a case management program designed to enhance primary care physician practice with older persons. J Appl Gerontol. 1999;18(1):25-45.

87. Seddon D, Robinson CA. Carers of older people with dementia: assessment and the Carers Act. Health Soc Care Community. 2001; 9(3):151-158.
88. van Eijken $M$, Melis R, Wensing M, Rikkert MO, van Achterberg T. Feasibility of a new community-based geriatric intervention programme: an exploration of experiences of GPs, nurses, geriatricians, patients and caregivers. Disabil Rehabil. 2008;30(9):696-708.

89. Waugh F. Where does risk feature in community care practice with older people with dementia who live alone? Dementia. 2009;8(2): 205-222.

90. Minkman MM, Ligthart SA, Huijsman R. Integrated dementia care in The Netherlands: a multiple case study of case management programmes. Health Soc Care Community. 2009;17(5):485-494.

91. Wright LK, Litaker M, Laraia MT, DeAndrade S. Continuum of care for Alzheimer's disease: a nurse education and counseling program. Issues Ment Health Nurs. 2001;22(3):231-252.

92. Cohen J. Weighted kappa: nominal scale agreement with provision for scaled disagreement or partial credit. Psychol Bull. 1968;70(4): 213-220.

93. Baugh RF, Freeman M. Ingredients of a successful case management program. Physician Exec. 2003;29(2):30-33.

94. Huston CJ. The role of the case manager in a disease management program. Lippincotts Case Manag. 2001;6(5):222-227.

95. Drennan V, Goodman C. Nurse-led case management for older people with long-term conditions. Br J Community Nurs. 2004; 9(12):527-533.

96. Pimlott NJ, Persaud M, Drummond N, Cohen CA, Silvius JL, Seigel $\mathrm{K}$, et al. Family physicians and dementia in Canada: Part 1. Clinical practice guidelines: awareness, attitudes, and opinions. Can Fam Physician. 2009;55(5):506-7 e1-e5.

97. Aminzadeh F, Molnar FJ, Dalziel WB, Ayotte D. A review of barriers and enablers to diagnosis and management of persons with dementia in primary care. Can Geriatr J. 2012;15(3):85-94.

98. Ferguson JA, Weinberger M. Case management programs in primary care. J Gen Intern Med. 1998;13(2):123-126.

99. Alzheimer Society of Ottawa and Renfrew County. Dementia Needs Assessment. 2013.

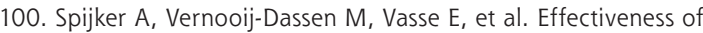
nonpharmacological interventions in delaying the institutionalization of patients with dementia: a meta-analysis. J Am Geriatr Soc. 2008;56(6):1116-1128.

101. Schulz R, Beach SR. Caregiving as a risk factor for mortality: the Caregiver Health Effects Study. JAMA. 1999;282(23):2215-2219.

102. Riordan J, Bennett A. An evaluation of an augmented domiciliary service to older people with dementia and their carers. Aging Ment Health. 1998;2(2):137-143. 